\title{
Megaloblastic anaemia after pelvic radiotherapy for carcinoma of the cervix
}

\author{
CG ANDERSON, KR WALTON, AND I CHANARIN \\ From the Northwick Park Hospital and Clinical Research Centre, Watford Road, Harrow, Middlesex, UK
}

SUMMARY A 71-year-old woman was treated with radiotherapy for carcinoma of the cervix. Nine years later she was found at laparotomy to have a thickened narrow ileum. At the time she had an iron-deficiency anaemia and when this was treated the blood picture changed to that of a severe megaloblastic anaemia. This was due to cobalamin deficiency resulting from malabsorption of cobalamin by the damaged ileum.

Loops of distal bowel in man are normally located in the pelvis, and it is the rule rather than the exception that irradiation to the pelvis, whether for a lesion of the bladder or of the cervix uteri, will produce radiation damage to these segments of distal bowel. The ileum is the site of absorption of vitamin $B_{12}$ and of bile salts. Other substances that may be absorbed in the ileum can also be absorbed by more proximal gut. Thus damage to the ileum only may lead to malabsorption of vitamin $B_{12}$ and bile salts.

Intestinal malabsorption after radiation therapy was first reported by Dodds and Webster in $1924 .^{1}$ Three cases of radiation enteritis were reported by Tankel et al., ${ }^{2}$ one of whom had a low serum $B_{12}$ level and another absorbed vitamin $B_{12}$ poorly. Ratzkowski and Hochman ${ }^{3}$ found $\mathbf{B}_{12}$ malabsorption in onethird of patients, the severity being related to the radiation dose. Eight out of 14 patients receiving cobalt teletherapy had malabsorption of $B_{12 .}{ }^{4}$

Three cases with megaloblastic anaemia after irradiation were reported by Duncan and Leonard. ${ }^{5}$ Two followed five to seven months after irradiation whereas a lag of more than five years is required to exhaust vitamin $\mathbf{B}_{12}$ stores after $\mathbf{B}_{12}$ absorption ceases. One of the patients was found to have an ileal stricture at necropsy. A third was said to have subacute combined degeneration of the cord two years after treatment. She was found to have normal $B_{12}$ absorption four years later. None of these cases is therefore acceptable as an example of megaloblastic anaemia due to radiation damage to the ileum. The following case report appears to be the first proven example of this situation.

Accepted for publication 13 August 1980

\section{Case report}

A 71-year-old woman presented in April 1979 to the haematology department with an iron-deficiency anaemia. Her symptoms were of a flu-like illness with loss of appetite and a weight loss of $6 \mathrm{~kg}$ over the preceding six weeks. She also admitted to altered bowel habit with occasional diarrhoea.

Examination revealed only a very thin woman with a smooth tongue. The haemoglobin concentration was $5.9 \mathrm{~g} / \mathrm{dl}, \mathrm{MCV} 73 \mathrm{fl}, \mathrm{MCH} 20.4 \mathrm{pg}, \mathrm{MCHC}$ $27.8 \%$, and WBC $2.6 \times 10^{9} / 1$. The stained blood film showed severe hypochromia. Serum iron was $3 \mu \mathrm{mol} / 1$ and total iron binding capacity $75 \mu \mathrm{mol} / \mathrm{l}$. Barium enema revealed a carcinoma in the ascending colon approximately $5 \mathrm{~cm}$ above the ileocaecal valve.

She had been on oral iron therapy with a rise in haemoglobin concentration to $10 \cdot 2 \mathrm{~g} / \mathrm{dl}$ but the MCV had risen to $98 \mathrm{fl}$ (normal range 80-92 fl) over the next five weeks. At operation an annular carcinoma was found and a right hemicolectomy was performed. It was also noted that 'the whole ileum was thickened and somewhat narrowed and had the appearance of post-irradiation change (pulses were good).'

The resected specimen consisted of $8 \mathrm{~cm}$ of terminal ileum and $19 \mathrm{~cm}$ of caecum and ascending colon and showed an infiltrating adenocarcinoma. The ileum was slightly thickened with rigid walls. Histology showed that it was oedematous but no other lesion was seen.

She made a good postoperative recovery and left hospital after three weeks. After her discharge she complained of diarrhoea at least five times a day which was extremely watery but in which there was no blood or mucus. Her $\mathrm{Hb}$ again dropped to 
$7.7 \mathrm{~g} / \mathrm{dl}$ but on this occasion her MCV was $115 \mathrm{fl}$ and she was admitted for reassessment. Because of the surgeon's comment regarding the features of her ileum, she was again questioned regarding previous illnesses and on this occasion she remembered having had an 'ulcer' on the womb treated with radiotherapy nine years previously, after which she developed distressing diarrhoea for some months.

Information from the radiotherapy department at Mount Vernon Hospital indicated that the patient had been treated on a $4 \mathrm{MeV}$ linear accelerator with an anterior and two posterior oblique fields. The volume was taken to a minimum tumour dose of 5460 rads in 23 treatments over 45 days. The field was $17 \mathrm{~cm}$ long and $14 \mathrm{~cm}$ wide.

Marrow aspiration performed four months after the operation was frankly megaloblastic with abundant iron stores. Serum vitamin $\mathbf{B}_{12}$ by bioassay was $35 \mathrm{pg} / \mathrm{ml}$ (normal $+170 \mathrm{pg} / \mathrm{ml}$ ) while serum and red cell folate were entirely normal. Tissue antibodies were not detected. Her faecal fat was $37.8 \mathrm{~g} / 24$ hours and tests of $B_{12}$ absorption were all abnormal (Table). All other tests of malabsorption including xylose absorption were normal. There was no increase in urinary indican.

Vitamin $B_{12}$ absorption studies (Schilling test)

\begin{tabular}{llll}
\hline & ${ }^{57} \mathrm{CO}_{-B_{12} \text { alone }}$ & $\begin{array}{l}{ }^{57} \mathrm{Co}-\mathrm{B}_{12} \text { with } \\
\text { intrinsic factor }\end{array}$ & $\begin{array}{l}{ }^{67} \mathrm{Co}-\mathrm{B}_{12} \\
\text { alone after } \\
\text { oxytetra- } \\
\text { cycline }\end{array}$ \\
\hline $\begin{array}{l}\%{ }^{67} \mathrm{Co}-\mathrm{B}_{12} \text { in urine } \\
\text { over } 24 \text { hours } \\
(\mathrm{N}+10 \%)\end{array}$ & 0.2 & 0.7 & 0.9 \\
$\begin{array}{l}\%{ }^{37} \mathrm{Co}-\mathrm{B}_{18} \text { per litre } \\
\text { plasma at } 10 \text { hours } \\
(\mathrm{N}+0.6 \%)\end{array}$ & 0.1 & & \\
\hline
\end{tabular}

To exclude bacterial overgrowth the $B_{12}$ absorption test was repeated after nine days of oxytetracycline and it remained abnormal. Endoscopy of the stomach and upper gut was normal. Gastric biopsy showed a normal mucosa, $\mathrm{pH}$ of the gastric juice was $1 \cdot 7$, and intrinsic factor was present in normal amounts. Jejunal biopsy showed mild partial villous atrophy with no cytological evidence of radiation damage.

\section{Discussion}

Damage to this patient's ileum was demonstrated at laparotomy nine years after irradiation to the pelvis and was confirmed histologically. The iron deficiency, due to loss of blood from a carcinoma of the colon, concealed an underlying megaloblastic anaemia and a macrocytic blood picture (noted before laparotomy) and, due to $B_{12}$ deficiency, appeared after iron therapy. Pernicious anaemia was excluded because of the presence of normal amounts of acid and intrinsic factor in the gastric secretion as well as by a normal gastric biopsy. There was steatorrhoea with malabsorption of $\mathrm{B}_{12}$ both alone and when given with intrinsic factor. Although mild villous atrophy raises the question of coeliac disease, this in fact does not produce megaloblastic anaemia due to $B_{12}$ deficiency as was the case in this patient.

\section{References}

${ }^{1}$ Dodds EC, Webster JHD. The metabolic changes associated with X-ray and radium treatment. Lancet 1924;1: 533-7.

2 Tankel HI, Clark DH, Lee FD. Radiation enteritis with malabsorption. Gut 1965;6:560-9.

${ }^{3}$ Ratzkowski E, Hochman A. Gastro-intestinal function after abdominal cobalt irradiation. Acta Radiol [Ther] (Stockh) 1968;7:417-32.

${ }^{4}$ McBrien MP. Vitamin $B_{12}$ malabsorption after cobalt teletherapy for carcinoma of the bladder. Br Med J 1973; $1: 648-50$.

${ }^{5}$ Duncan W, Leonard JC. The malabsorption syndrome following radiotherapy. $Q J$ Med $1965 ; 34: 319-29$.

Requests for reprints to: Dr I Chanarin, Northwick Park Hospital and Clinical Research Centre, Watford Road, Harrow, Middlesex HA1 3UJ. 